\title{
Ênfases no ensino de escrita: tema, estilo e construção composicional em livros escolares de português
}

DOI: http://dx.doi.org/10.21165/el.v49i2.2655

\section{Cristian Henrique Imbruniz ${ }^{1}$}

\section{Resumo}

Este trabalho apresenta a análise de propostas de escrita de dezesseis livros escolares de português publicados no período de 1930 a 2002, no Brasil. Descartando qualquer suposição de que a noção de gênero do discurso (BAKHTIN, 2016) tenha sido mobilizada como instrumento didático naqueles livros, as propostas são descritas com base no conteúdo temático, no estilo e na construção composicional, elementos do gênero de discurso utilizados como ferramentas teórico-metodológicas, aqui apresentadas na análise do livro Português para o ginásio, de Cretela (1948). O objetivo do trabalho foi determinar qual desses elementos é o mais enfatizado nos livros do período. Os resultados indicam que, entre 1930 e 1960, predominou a ênfase no conteúdo temático e, a partir de 1970, na construção composicional.

Palavras-chave: livros escolares; escrita; propostas de escrita; dialogismo.

1 Universidade de São Paulo (USP), São Paulo, São Paulo, Brasil; imbrunizc@gmail.com; https://orcid.org/0000-0001-6506-9285 


\title{
Emphasis on teaching writing: thematic content, style and compositional structure in Brazilian Portuguese textbooks
}

\begin{abstract}
This work presents the analysis of the writing proposals from sixteen Portuguese textbooks. Those books were published between 1930 and 2002, in Brazil. Discarding any supposition that the notion of speech genre (BAKHTIN, 2016) may be used as didactic instrument in those books, the writing proposals are described according to thematic content, style and compositional structure, speech genre elements used as theoreticalmethodological tools, here presented in the analysis of Português para o ginásio, a textbook by Cretela (1948). The aim of this work is to determine which of those elements is the most emphasized on the textbooks of the period. The results indicate that, between 1930 and 1960, prevailed the emphasis on thematic content and, from 1970 onwards, on compositional structure.
\end{abstract}

Keywords: textbooks; writing; writing proposals; dialogism.

\section{Introdução}

Em dissertação de mestrado (IMBRUNIZ, 2019), intitulada Elementos para uma memória discursiva do ensino de escrita: livros escolares de português (1930-2002), estabeleço elementos para uma memória discursiva do ensino de escrita, apreendida a partir da investigação de livros do período de 1930 a 2002, destinados ao último ano do primeiro ciclo do ensino secundário brasileiro (atual nono ano do ensino fundamental 2). Para tanto, analiso oito livros escolares de português destinados a esse nível de ensino, tendo selecionado um livro para cada década iniciada no período recortado (um livro para 1930, um para 1940 e assim sucessivamente, até 2002). No presente artigo, as ideias desenvolvidas dão sequência ao que foi discutido na dissertação, da qual foram aproveitados alguns trechos.

Para chegar aos oito livros escolares que compõem o corpus final da pesquisa em questão, estabeleci dois critérios de seleção do material. Ao primeiro, chamei critério autoral-editorial, cuja aplicação visava encontrar e, em seguida, selecionar, dezesseis livros escolares, considerando-se os dados de produção/circulação/recepção dos livros, tais como número de edição, tiragem, casa editorial, autor, dentre outros. Como esses dados editoriais são, frequentemente, encontrados de forma esparsa e pouco sistematizada, em trabalho anterior (IMBRUNIZ, 2018), defendo que sejam tomados em estado de ruína², pois penso que são como dados em ruína que podem ser capturados no acontecimento

2 Em Imbruniz (2018, 2019), tomo emprestado o termo ruína de Corrêa (2006), que o emprega para apreender vestígios da presença de certos gêneros em outros. Aplicada a dados editoriais 
discursivo (PÊCHEUX, 2015) da produção/circulação/destinação dos livros escolares. Reunidos e interpretados os dados editoriais em ruína, foi possível obter elementos suficientes para encontrar, em documentos específicos ${ }^{3}$, livros escolares que pudessem ser considerados como mais expressivos de cada década, mesmo que a escolha fosse sempre relativa aos critérios estabelecidos e, portanto, não chegasse nunca ao "dado limite", isto é, não chegasse a encontrar, de modo absoluto, "o" livro mais representativo.

Ao segundo critério, chamei enunciativo-discursivo ${ }^{4}$, e sua aplicação visava descrever e organizar os dezesseis livros escolares selecionados pelo primeiro critério. Finalmente, por meio da síntese entre os dois critérios apresentados, selecionei oito desses dezesseis livros, correspondentes às oito décadas iniciadas no período.

É justamente do critério enunciativo-discursivo que trato neste trabalho. Como ficou dito, para descrever as propostas de escrita de livros escolares de português, proponho, como ferramenta teórico-metodológica, os elementos do gênero discursivo bakhtiniano, a saber, conteúdo temático, estilo e construção composicional (BAKHTIN, 2016), verificando, em cada proposta de escrita, qual desses elementos foi o mais enfatizado. Um dos interesses dessa abordagem é a possibilidade que esses elementos abrem - por serem constitutivamente dialógicos, a exemplo do próprio gênero do discurso - de explorar o fato de que eles são também marcados sócio-historicamente.

A propósito, contra a frequente crítica do cunho descritivista das pesquisas sobre livros escolares, esclareço o sentido que dou a "descrever" neste trabalho. Com a aplicação do critério enunciativo-discursivo, não pretendo reproduzir elementos da estrutura externa e interna ou do conteúdo dos livros escolares. Pelo contrário, ao descrever as propostas de escrita pela observação dos três elementos do gênero do discurso, pretendo captar o movimento que, sócio-historicamente, atua na elaboração dessas propostas e no próprio ensino da escrita.

de preservação irregular, a noção de ruína os considera não só por sua incompletude, mas por sua "eficácia como fonte histórica", pois são um "aspecto positivo de um dado (textual-discursivo ou não)", o qual, mesmo que incompleto, permite recuperar uma história (CORRÊA, 2006, p. 209).

3 Refiro-me às listas de livros aprovados, entre 1938 e 1961, pela Comissão Nacional do Livro Didático (CNLD), às listas de livros recomendadas, entre 1985 e 2005, pelo Programa Nacional do Livro Didático (PNLD) e aos livros disponíveis em dois acervos específicos, o da Biblioteca do Livro Didático, da Faculdade de Educação, da USP (BLD-USP) e o do acervo da Companhia Editora Nacional, do Centro de Memória e Pesquisa Histórica, da UNIFESP (CMPH-UNIFESP).

4 Em Imbruniz (2018), o segundo critério é chamado linguístico-discursivo. Optei posteriormente por chamá-lo enunciativo-discursivo, já que a referência ao aspecto linguístico, embora sempre presente na enunciação e no discurso, poderia gerar confusão quanto ao alcance pretendido, que é o do fenômeno linguístico em seu uso concreto (em enunciação) e de sua relação com a história (no discurso). 
O objetivo deste artigo é, portanto, determinar qual desses elementos é o mais enfatizado nos dezesseis livros selecionados no período entre 1930 e 2002, em diálogo com uma perspectiva teórica, no caso fundada no campo dos estudos discursivos, em especial, da Análise do discurso francesa e da Análise dialógica do discurso, como é conhecida, no Brasil, a contribuição de Bakhtin e do Círculo. Desse objetivo geral, decorrem dois objetivos específicos, a saber: (i) verificar a aplicabilidade dos elementos do gênero do discurso como ferramenta analítica rigorosa para livros escolares de diferentes períodos; e (ii) chegar a tendências quanto ao ensino de escrita no período compreendido entre 1930 e 2002.

Para cumprir com esses objetivos, apresento, como informação teórica prévia, os elementos do gênero do discurso, defendendo o caráter dialógico de cada um deles. Em consonância com os objetivos específicos, discuto, em seguida, os resultados da pesquisa de mestrado, buscando indicar, no tratamento do livro Português no ginásio, de José Cretela (1948) - pertencente ao corpus da pesquisa -, o modo de análise e as especificidades que cada obra pode apresentar.

\section{0 dialogismo nos elementos do gênero discurso}

Em Os gêneros do discurso, Bakhtin diferencia a oração (unidade da língua) do enunciado concreto (unidade da comunicação discursiva ${ }^{5}$ ), considerando que os enunciados são "concretos, únicos, proferidos pelos integrantes desse ou daquele campo de atividade humana" (BAKHTIN, 2016, p. 11), mantendo, portanto, relação com outros enunciados já proferidos e, também, antecipando a possibilidade de proferimento de certos outros enunciados. A oração, segundo o autor, "não tem contato imediato com a realidade (com a situação extraverbal) nem relação imediata com enunciados alheios" (BAKHTIN, 2016, p. 33). Pelo contrário, a oração teria contato somente com outras orações, carecendo da capacidade de determinar uma resposta.

Com a distinção entre enunciado concreto e oração, dentre outras coisas, Bakhtin estabelece o dialogismo como constitutivo da linguagem verbal, na medida em que "toda compreensão da fala viva, do enunciado vivo é de natureza ativamente responsiva (embora o grau desse ativismo seja bastante diverso)" (BAKHTIN, 2016, p. 25).

Ainda segundo o autor, os enunciados concretos são reflexo de condições específicas dos campos de atividade humana nos quais são engendrados, tomando formas relativamente estáveis, chamadas gêneros do discurso (BAKHTIN, 2016), indissoluvelmente constituídos

5 Para os leitores brasileiros, consolidou-se a tradução "comunicação verbal", presente no volume publicado pela Martins Fontes, em 1992 e em 1997, feita a partir do francês. Neste artigo, porém, para fins de atualização, adoto a tradução publicada pela Editora 34, feita diretamente do russo, em que aparece "comunicação discursiva" em lugar de "comunicação verbal". 
por conteúdo temático, estilo e construção composicional. Esses três últimos elementos refletem, efetivamente, as condições e especificidades de cada campo de atividade humana, de tal modo que se pode verificar, em cada um deles, a constituição do dialogismo.

De saída, interessa destacar que as definições de Bakhtin para cada um dos elementos do gênero do discurso fogem à sua apreensão mais comum. Começo pelo estilo. Quando tratada pela estilística tradicional, a noção de estilo se orienta pela individualidade. Não é raro pensar que o estilo, principalmente quando se fala em produção artística, é individual e, de certo modo, caracteriza o artista. No caso do enunciado concreto, o estilo não está na intencionalidade do enunciador, mas funciona como um epifenômeno e produto complementar do uso da língua (BAKHTIN, 2016). O estudo do estilo deve, portanto, basear-se no estudo preliminar dos gêneros do discurso, tomando em conta toda a sua diversidade. Bakhtin (2016, p. 19) afirma que "até hoje a estilística da língua careceu de semelhante base", e conclui, "daí a sua fraqueza".

O estilo, considerado como epifenômeno e produto complementar do uso da língua, abdica da individualidade como força motriz para privilegiar a característica dialógica que descreve o funcionamento da linguagem verbal em Bakhtin. Em outros termos, não é a individualização que constitui o estilo de um gênero discursivo, mas um movimento dialógico que opera na regulação do enunciado e do gênero. Segundo Bakhtin (2016, p. 59), "o enunciado é pleno de tonalidades dialógicas, e sem levá-las em conta é impossível entender até o fim o estilo de um enunciado".

Feitas essas especificações para a noção de estilo, passo para a de construção composicional. Na mesma direção do estilo, ela não corresponde a nenhuma prescrição no que se refere à forma de um gênero do discurso. A construção composicional obedece ao mesmo funcionamento dialógico da linguagem verbal e, por isso, caracteriza-se por se constituir como produto de relações dialógicas. Bakhtin $(2016$, p. 63) acrescenta que perguntas como "A quem se destina o enunciado?", "Como o falante (ou o que escreve) percebe e representa para si os seus destinatários?", "Qual é a força e a influência deles no enunciado?" são fundamentais para se pensar a construção composicional. Os gêneros trariam, nesse sentido, construções composicionais híbridas, já que, considerado o destinatário, um dado gênero pode ser mais bem recebido caso se aproxime de tal outro e, portanto, de tal outra construção composicional. O que está em jogo nesse modo de compreender a construção composicional é a assunção do reinvestimento do diálogo (CORRÊA, 2013) como maneira de observar a dinamicidade do gênero, que pode ser apreendida pelas relações intergenéricas. Mais uma vez, portanto, é pela afirmação da dialogia e da relação com o outro que a construção composicional atua na constituição do gênero do discurso. 
A direção da reflexão feita sobre o estilo e a construção composicional se mantém para o conteúdo temático. Este só pode ser apreendido se considerado dentro de uma perspectiva dialógica. Não se trata simplesmente de responder à pergunta "Qual é o objeto de sentido?", mas de verificar a circulação de um tema (e como ele é afetado) por diferentes campos de atividade humana e, também, as conexões estabelecidas entre diversos temas, os quais, circulando por diferentes campos, compõem o conteúdo temático de um gênero discursivo, mesmo estando associados a um campo diferente do gênero inquirido quanto ao seu objeto de sentido.

A partir dessa breve recapitulação, pode-se sugerir que a conformação do gênero do discurso atende ao movimento da (sua) história e que seus três elementos estão também atrelados ao movimento dialógico da linguagem e, portanto, aos campos de atividade humana e à história. Parece, pois, pertinente levantar a seguinte hipótese: é possível detectar tendências no ensino de escrita em livros escolares de português num dado período de tempo, no caso, entre 1930 e 2002, desde que observemos, num nível que escapa à vontade ou à idiossincrasia do seu autor empírico, o modo como esses três elementos, individualmente ou em conjunto, são enfatizados nas propostas de ensino de escrita; ou seja, o modo como se chegaria, pela via do enunciado concreto (BAKHTIN, 2016), à singularidade histórica de cada um desses livros, a fim de estabelecer categorias suficientemente fortes para detectar tendências no ensino de escrita.

Não assumo, portanto, os elementos do gênero do discurso como um modo de classificação de gêneros, de propostas de escrita ou de livros escolares. Pelo contrário, assumo-os como uma possibilidade de reencontrar o histórico, de forma sistemática, nas propostas de escrita de diferentes períodos. A captura do movimento que, sócio-historicamente, atua na elaboração das propostas de escrita dos livros escolares e no próprio ensino de escrita é um aspecto fundamental da ferramenta analítica que proponho, permitindo oferecer uma análise dessas propostas e de suas ênfases quanto à conjuntura sociopolítica de sua publicação. Entendo que a delimitação de uma conjuntura sociopolítica se dá pela consideração da instauração histórica (bem-sucedida ou não) do social no político. Uma conjuntura sociopolítica supõe, portanto, a necessária consideração da historicidade do social nas intervenções aparentemente apenas organizacionais, mas que, de fato, atuam para impor, manter ou retirar poder de diferentes instâncias sociais, o que, no caso do ensino, pode ser constatado nos pontos visíveis desse iceberg, tais como nas ordenações jurídico-administrativas (reformas educacionais e toda a espécie de documentos oficiais, incluindo leis, currículos e critérios institucionais de avaliação de livros escolares) e, como defendo aqui, também na produção de livros escolares e em suas propostas de ensino e de ensino de escrita.

Busco, pois, conceber determinadas particularidades históricas de cada conjuntura como constitutivas das diferentes ênfases, de modo a estabelecer tendências gerais no ensino de escrita. Não se trata, portanto, de uma determinação de uma dada conjuntura que 
poderia, sob a forma de um fator externo, afetar uma dada escolha no tipo de ênfase das propostas de escrita de um livro escolar. Não se trata - menos ainda - de uma associação mecanicista que atribuísse essas escolhas à contemporaneidade de um acontecimento sociopolítico de relevo ou à coincidência temporal entre a data de publicação do livro e a publicação de um documento oficial. Afasto, portanto, qualquer possibilidade de justificação daquelas ênfases como ligadas, de forma imediata, com uma reforma educacional ou com uma ruptura política. Ao contrário, assumo que a intervenção de uma conjuntura sociopolítica se dá pela instauração do social - o histórico-social - no político. Desse modo, assumindo a necessária consideração de uma "história social dos textos" na constituição do arquivo, tal como proposto por Guilhaumou e Maldidier (2014, p. 170), procuro observar as ênfases nas propostas de escrita como marcos de posicionamentos historicamente determinados.

\section{Tendências do ensino de escrita (1930-2002): 16 livros escolares de português}

Conforme mostra o quadro $1^{6}$, segundo o critério enunciativo-discursivo, foram analisados 16 livros escolares.

Antes de apresentar os dados e os resultados da análise sob a forma de tendências gerais para o ensino de escrita, faço uma observação quanto a possíveis sugestões de anacronismo na aplicação da ferramenta de análise proposta. Naturalmente, sua aplicação não tem por objetivo encontrar elementos de uma teoria dialógica da linguagem em autores de livros escolares de português. Deve-se observar que o critério enunciativo-discursivo utiliza os elementos do gênero do discurso como ferramenta de análise, verificando, em cada proposta de escrita, qual(is) desse(s) elemento(s) foi o mais enfatizado. É importante lembrar, porém, que utilizá-los metodologicamente na operacionalização da análise nada tem a ver com buscar qualquer tipo de aplicação prática desses conceitos por parte dos autores desses livros de português.

No total, os 16 livros apresentam 544 propostas de escrita, nas quais identifiquei, individualmente, a ênfase dada a um único ou a combinações dos elementos do gênero do discurso. Como era de esperar, há idiossincrasias no material, das quais destaco a que considero principal: o fato de que alguns livros apresentam muito mais propostas de escrita do que outros, fazendo com que suas ênfases predominem no conjunto geral com força de tendência. Todavia, esse problema serve como um primeiro índice para análise. A maioria dos livros, se não todos, que oferecem mais de 50 propostas de escrita foram publicados até o fim da década de 1960. Os livros publicados a partir de 1970 tendem a apresentar, no máximo, 30 propostas, no mais das vezes, sem chegar a 20 delas, com

6 Considere-se: CT: Conteúdo temático; Est: Estilo; e CC: Construção composicional, bem como suas combinações. 
apenas uma exceção, o livro Reflexão e ação em língua portuguesa, de Prates, que oferece 41 propostas e foi publicado em 1984.

Quadro 1. Distribuição dos elementos do gênero do discurso (1930-2002)

\begin{tabular}{|l|c|c|c|c|c|c|c|}
\hline \multicolumn{1}{|c|}{ Livro/Ano } & CT & Est & CC & CC/E & CC/CT & E/CT & T \\
\hline Método de redação, de Góes (1930) & 0 & 0 & 0 & 0 & 68 & 0 & 68 \\
\hline O nosso idioma, de Freitas (1938) & 67 & 0 & 0 & 0 & 54 & 0 & 121 \\
\hline Português para o ginásio, de Cretela (1947) & 14 & 0 & 3 & 13 & 5 & 0 & 35 \\
\hline Curso de português, de Barros (194?) & 29 & 0 & 4 & 1 & 2 & 2 & 38 \\
\hline Quarto livro de português, Costa (1950) & 14 & 0 & 2 & 2 & 3 & 0 & 21 \\
\hline Português ginasial, de Luz (1951) & 2 & 0 & 0 & 0 & 3 & 0 & 5 \\
\hline Português, de Cegalla e Rocher (1964) & 75 & 0 & 0 & 2 & 5 & 0 & 82 \\
\hline $\begin{array}{l}\text { Português através de textos, de Soares } \\
\text { (1969) }\end{array}$ & 9 & 1 & 0 & 2 & 1 & 2 & 15 \\
\hline $\begin{array}{l}\text { Ativ. de comunicação em língua portuguesa, } \\
\text { de Sargentim (1974) }\end{array}$ & 4 & 0 & 1 & 3 & 6 & 1 & 15 \\
\hline $\begin{array}{l}\text { Português dinâmico, de Siqueira e Bertolin } \\
\text { (197?) }\end{array}$ & 16 & 0 & 5 & 0 & 6 & 1 & 28 \\
\hline $\begin{array}{l}\text { Reflexão e ação em língua portuguesa, de } \\
\text { Prates (1984) }\end{array}$ & 6 & 0 & 6 & 2 & 25 & 2 & 41 \\
\hline $\begin{array}{l}\text { Linguagem, leitura e produção de texto, de } \\
\text { Megale e Matsuoka (1984) }\end{array}$ & 4 & 0 & 5 & 1 & 2 & 0 & 12 \\
\hline $\begin{array}{l}\text { Análise, linguagem e pensamento, de Heiler } \\
\text { e Cócco (1993) }\end{array}$ & 1 & 0 & 6 & 3 & 7 & 0 & 17 \\
\hline Linguagem nova, de Faraco e Moura (1993) & 4 & 0 & 7 & 3 & 3 & 1 & 18 \\
\hline Português: texto e voz, de Tesoto (2002) & 7 & 0 & 2 & 1 & 3 & 0 & 13 \\
\hline $\begin{array}{l}\text { Português: leitura, gramática e produção, de } \\
\text { Sarmento (2002) }\end{array}$ & 3 & 1 & 5 & 1 & 5 & 0 & 15 \\
\hline Total & 255 & 2 & 46 & 34 & 198 & 9 & 544 \\
\hline
\end{tabular}

Fonte: Elaboração própria

Chama a atenção, no conjunto de dados do quadro 1, a predominância da ênfase no conteúdo temático e no conteúdo temático associado à construção composicional. Dentre as 544 propostas analisadas, 251 enfatizavam o conteúdo temático e 198 o conteúdo temático associado à construção composicional. Esses valores correspondem quase à totalidade das propostas, mas a análise detida revela particularidades. Quanto 
à ênfase no conteúdo temático, pode-se dizer que ela é predominante de 1930 a 1960. Nesse mesmo período, predominava, também, o que venho chamando de propostassintagma, isto é, propostas de escrita em que há um ou mais sintagmas nominais, com ou sem complementos ou modificadores, determinando um tema específico, precedido(s) de um comando de exercício marcado por ruptura sintática, na forma de descrição da tarefa a ser realizada, como em "Tema para redação: saudade" (CEGALLA, 1966, p. 81). No caso do último exemplo, "tema para redação:" seria a descrição da tarefa a ser realizada e "saudade" a proposta-sintagma propriamente dita. A grande frequência desse tipo de proposta nos livros publicados entre 1930 e 1960 levaria ao estabelecimento de uma tendência para o período: a ênfase no conteúdo temático.

A ênfase no conteúdo temático associado à construção composicional pode ser explicada como um ponto de "tensão" que perpassa todo o período analisado, revelando o embate entre duas tendências no ensino de escrita. Por um lado, o predomínio da ênfase no conteúdo temático. Esse predomínio é inquestionável. No entanto, mesmo nas propostassintagma, impunha-se, por outro lado, alguma exigência ligada a traços composicionais, como, por exemplo, a exigência de tipos textuais/gêneros escolares específicos, como em "Tema para exercício de redação: dissertação: o sol" (FREITAS, 1938, p. 163). Essa ênfase conjunta sugere que, durante quase todo o período analisado, tomavam-se esses dois elementos como fundamentais para se ensinar a escrita, talvez porque sejam os que representem o que há de mais estável nos gêneros do discurso, destacadamente a construção composicional ${ }^{7}$.

Ainda a esse respeito, vale observar, no conjunto de dados, que, a partir de 1970, a ênfase no conteúdo temático começa a perder força, ao passo que o destaque na construção composicional, sozinho ou em conjunto com outro elemento, passa a crescer. É verdade que os índices são comparativamente baixos em relação ao destaque que o conteúdo temático teve em outras décadas. Isso, no entanto, pode ser explicado pela frequência relativamente baixa de propostas de escrita, que, a partir de então, passam a ser menos frequentes nos livros escolares de português, de modo geral. Talvez a queda no número de propostas seja explicada por mudanças gráfico-editoriais que aconteceram na década de 1970. Segundo Batista (1999), os livros escolares de português passaram a ser mais procedimentais e menos conteudísticos, consolidando o modelo hoje conhecido com seções de gramática, literatura e produção textual. Essa nova configuração pode ter concorrido para a diminuição do número de propostas de escrita, tornando-as mais "especializadas" (portanto, menos "genéricas" do que as inúmeras propostas-sintagma). Retenha-se, dessa breve discussão, que, embora não atinja números altos, a ênfase na construção composicional se torna a mais representativa nessa década.

7 No presente trabalho, não é possível desenvolver essa discussão em detalhes. Para um tratamento aprofundado, cf. Imbruniz (2019), parte I, capítulo 2; e parte II, capítulo 2. 
A partir da distribuição da frequência das ênfases nos elementos do gênero do discurso presentes em dezesseis livros publicados entre 1930 e 2002, é possível afirmar que (1) entre 1930 e 1960, predominou o conteúdo temático, embora a construção composicional já despontasse como concorrente, mas ainda associada ao conteúdo temático; (2) a partir dos anos 1970 até 2002, o número de propostas de escrita passa a ser menor, mas é possível observar o crescimento proporcional da ênfase na construção composicional em detrimento do até então dominante conteúdo temático; e que (3) o estilo não teve um papel destacado nas atividades de produção textual sugeridas nos livros escolares analisados, embora, entre 1930 e 1960, note-se a dominância de uma concepção "beletrista" de língua, traduzida na ideia de língua como expressão estética e do texto literário como modelo a ser seguido (a esse respeito, cf. MEDEIROS, 2019). Em Imbruniz (2019, p. 171), defendo que a baixa ênfase no estilo nas propostas de escrita se deve ao fato de que ele já seria abordado nas seções de estudo gramatical, especialmente, de sintaxe, pois, entre 1930 e 1960, 'é como se a sintaxe, o nível mais 'alto' de análise [gramatical], condensasse todo o conteúdo gramatical por meio de operações lógicas, através das quais se chegaria à escrita ou, pelo menos, se chegaria a favorecer a qualidade lógica e estilística da escrita".

Observe-se, ainda, que, embora as mesmas ênfases permaneçam por longos períodos, como, por exemplo, aquela que é marcada pela construção composicional de 1970 a 2002, em cada momento, elas se pautam por razões sociopolíticas particulares. Basta observar que, na década de 1970, o predomínio da ênfase na construção composicional, baseada numa concepção de língua como instrumento de comunicação, não se dá pela mesma razão que, nos anos 1980, quando as contribuições da linguística começavam a ser sistematizadas e aplicadas na escola ${ }^{8}$. Observe-se que a concepção de língua como instrumento de comunicação está ligada ao projeto desenvolvimentista da ditadura militar brasileira - em especial, na década de 1970 -, como defende Soares (2002), e o esforço de aplicação do conhecimento gerado nas universidades, no caso, o das ciências da linguagem, poderia ser atribuído à resposta a um clima de ressaca política durante a redemocratização, em que era preciso reagir aos anos de censura e ao regime de força - em especial, a partir da década de 1980 -, como, uma vez mais, aponta Soares (2002).

Dessa forma, pode-se afirmar que, conquanto a ênfase seja no mesmo elemento - a construção composicional -, ela se dá por razões diferentes. Por um lado, na década de 1970, como generalização de uma visão instrumentalista aplicada à linguagem, corolário do fortalecimento do projeto desenvolvimentista da ditadura militar para o qual, dentre outras variáveis, todas as coisas importavam pelo valor que pudessem representar como instrumento daquele projeto. Por outro lado, na década de 1980, como resposta crítica da sociedade, em especial, dos cientistas da linguagem, a essa mesma ditadura.

8 A esse respeito, cf. Soares (2002), em artigo sobre a história do português como disciplina curricular. 
A contribuição da ferramenta analítica aqui utilizada é, pois, oferecer uma análise detida das propostas de escrita de livros escolares e de suas ênfases quanto aos elementos do gênero do discurso, assumindo que, ao aspecto verbal dessas ênfases, corresponde o fato de que elas são também constituídas pelo histórico-social que atravessa transversalmente uma conjuntura sociopolítica. Salvaguardado o reconhecimento de tendências gerais, é preciso lembrar, no entanto, que livros escolares podem negar ou repor tendências que Ihe são anteriores, confirmar ou alterar aquelas contemporâneas a eles ou antecipar as que ainda estão por se constituir. Dito de outro modo, as tendências gerais detectadas na análise quantitativo-qualitativa não são estanques. Ao contrário, pode-se sugerir que, constituindo-se no processo discursivo, elas são marcadas pela diversidade de direções, o que se pode observar nas investigações de um livro escolar particular. Nessas análises particularizadas, constata-se - no caso deste trabalho, por meio do critério enunciativodiscursivo - ao mesmo tempo, tendências gerais (devidamente quantificadas), ao lado da convivência entre essas tendências gerais e especificidades relacionadas à própria obra, estas últimas apreendidas pela face qualitativa do mesmo critério.

\section{O caso de Português para o ginásio, de José Cretela}

O livro Português para o ginásio foi publicado em dois formatos pela Companhia Editora Nacional. Em 1945, foi publicado em volumes individuais, isto é, um para cada uma das quatro séries do ginásio. Essa publicação aparece nas listas da Comissão Nacional do Livro Didático (CNLD) ${ }^{9}$ sob o número de processo 76.350-45. Importa destacar o número de processo, pois, analisando as listas, nota-se que, provavelmente, os dois últimos dígitos indicam a data de submissão do livro à Comissão. Português para o ginásio teria sido, pois, submetido em 1945 e teria tido a aprovação publicada em 1947. No entanto, ainda em 1947, esse livro escolar passou a ser publicado aos pares, isto é, um volume para a $1^{\text {a }}$ e a $2^{a}$ série ginasiais e outro para $3^{a}$ e $4^{a}$ série ginasiais. Essa publicação aparece nas listas da CNLD ${ }^{10}$ sob o número de processo 46.258-47. Teria sido, portanto, submetida à Comissão em 1947 e teria tido a aprovação publicada em 1950.

Como o volume selecionado para este trabalho é duplo, para $3^{\mathrm{a}}$ e $4^{\mathrm{a}}$ séries, tomo 1947 como data de publicação da $1^{a}$ edição. No acervo da Nacional (CMPH-UNIFESP), só foram conservadas as fichas de circulação dos volumes duplos, cujo registro começa em 1947. Na verdade, vale observar que o formato que prosperou e fez bastante sucesso foi, justamente, o de volumes duplos, pois representa ganhos para a editora (produz-se um único volume para duas séries, gastando menos material e mão de obra) e para os alunos e suas famílias (compra-se somente um livro a cada duas séries).

9 Lista publicada no Diário Oficial da União, ano LXXXVI, nº 271, em 24 de novembro de 1947.

10 Lista publicada no Diário Oficial da União, ano LXXXIX, nº 186, em 12 de agosto de 1950. 
Português para o ginásio foi reeditado entre 1947 e 1962. Nesse intervalo, o conjunto, como um todo, atingiu 812.000 exemplares, sendo que 528.000 correspondiam ao volume de $1^{a}$ e $2^{a}$ séries e 284.000 correspondiam ao volume de $3^{a}$ e $4^{a}$ séries $^{11}$. Tal disparidade pode ser explicada pelo alto índice de evasão no ensino secundário (sobre o problema da permanência das classes baixas na escola pública na década de 1940, cf. FREITAS; BICCAS, 2009). De todo modo, Português para o ginásio foi um sucesso editorial, chegando a quase 1 milhão de exemplares e circulando por cerca de 15 anos. Analisando os dados apresentados, pode-se considerá-lo como um dos livros escolares de português mais expressivos da década de 1940.

Na edição de 1948, com que trabalho, a parte do livro dedicada à $4^{a}$ ginasial se divide em 72 lições e em 3 unidades gramaticais, a saber, (1) Palavra: vocábulo e têrmo, (2) Indoeuropeu e latim; e (3) Estudo breve e elementaríssimo de fonética histórica. O mesmo intertítulo "unidade" organiza o livro em dois níveis.

Num primeiro nível, no corpo do texto, a "unidade" (I, II ou III) corresponde a uma das seções de cada lição. Nas 72 lições, as seções se organizam em torno de um texto base, geralmente uma carta, e, com alguma variação, estão ordenadas da seguinte maneira: (1) Texto; (2) Vocabulário; (3) Unidade I (II ou III); (4) Para bem redigir cartas; (5) Exercícios; e (6) Biografia. Chama a atenção a seção (4), que se estende por toda a Unidade I. Em pequenos passos, o autor ensina como redigir bem uma carta (o que é uma carta, como preencher o envelope, tipos de carta etc., enfatizando, sobretudo, elementos estilísticos e composicionais). Voltarei a ela mais adiante.

Num segundo nível, no sumário (que aparece no final do livro), as "unidades" são destacadas e, em paralelo com um índice dos textos de abertura das lições, organizam os três blocos de temas gramaticais. Lembrando que o livro em questão continha uma parte para a $3^{a}$ série e outra para a $4^{a}$ série ginasiais, a organização dos conteúdos gramaticais da parte referente ao livro da $4^{a}$ série, quando tomado como um todo, corresponde à reprodução parcial do programa de português para essa série, o qual é exibido pelo autor logo no início dessa parte.

Como hipótese, pode-se dizer que essa duplicidade do intertítulo "unidade" é índice da gênese de um tipo de livro de português que, segundo o que penso, não seria propriamente a justaposição de seleta de textos e gramática - posição defendida por Soares (2002) -, mas um objeto gráfico novo, caracterizado por uma distribuição singular dos conteúdos no seu espaço gráfico, conforme defendo em Imbruniz (2019).

11 Dados obtidos no acervo da Companhia Editora Nacional, no CMPH-UNIFESP. 
As propostas de escrita aparecem na seção (5) Exercícios, postadas sempre ao final de cada lição. Ora, a indicação temática dessa seção é, obviamente, a de que se exercitará algo já comentado e, sendo a proposta de escrita o que aparece na sequência, pode-se concluir que a produção escrita é um exercício relacionado a algo desenvolvido numa das unidades gramaticais. Fica, pois, sugerida uma concepção de escrita que se funda na gramática da língua, o que pode ser lido segundo uma dupla continuidade: (a) da língua para o texto (escrito) - uma continuidade conceitual (não se pode esquecer de que a língua era comumente identificada à escrita); (b) do ensino de gramática (das unidades menores para as maiores, mas, preferencialmente, da sintaxe) para a prática de escrita uma continuidade didática, como desdobramento conceitual da anterior. Ao todo, são 35 propostas de escrita, sob o título "Redação", distribuídas entre as 72 lições.

Note-se que, na Unidade I, há uma particularidade. Trata-se da presença de 14 ocorrências da seção Para bem redigir cartas, correspondendo, tematicamente, a 14 propostas de escrita. Destaque-se, porém, que, nas propostas, que, como disse, sempre aparecem ao final da lição, não se exercitam propriamente os elementos explicados pelo autor em Para bem redigir cartas. Cada proposta de escrita corresponde a um exercício com o gênero carta, com atenção especial para diferentes situações sociais (carta de pêsames, carta a um sentenciado, carta de pedido etc.) e para diferentes formas de tratamento. 0 final da apresentação das 14 ocorrências da seção Para bem redigir cartas na Unidade I coincide com o final das instruções sobre ensino de escrita e sobre gêneros específicos, o que não impede que continuem a ser propostos exercícios de escrita não acompanhados de instrução explícita.

Vejamos como se distribuem as ênfases nos elementos do gênero do discurso no livro em questão.

Quadro 2. Ênfases nos elementos do gênero do discurso em Português para o ginásio.

\begin{tabular}{|c|c|c|c|c|c|c|c|}
\hline Livro/Ano & CT & Est & CC & CC/E & CC/CT & E/CT & T \\
\hline Português para o ginásio (1940) & 14 & 0 & 3 & $13^{12}$ & 5 & 0 & 35 \\
\hline
\end{tabular}

Fonte: Elaboração própria

O quadro 2 mostra que, nesse livro, a distribuição das ênfases é variada, destacando-se conteúdo temático (14 ocorrências) e construção composicional/estilo (13). Essa ênfase diversificada leva a duas observações importantes. A primeira, referente à ênfase no

12 Embora a seção Para bem escrever cartas seja predominantemente classificada aqui como enfatizando a construção composicional/estilo, há um único exemplo em que ela foi classificada apenas como construção composicional, já que a proposta de escrita omitia a referência à forma de tratamento, critério que adotei para determinar o destaque ao estilo. 
conteúdo temático, diz respeito ao destaque no plano pragmático, que, nesse caso, é tomado, mesmo quando se revela um tema repetido, preso ao calendário ou desprovido de apelo polêmico, como ponto de partida da interação a se estabelecer na produção escrita. A segunda, referente à ênfase na construção composicional/estilo, relativa também ao plano pragmático, não toma, porém, esse plano como ponto de partida da produção escrita no sentido de classificá-lo como mobilizador da interação, mas no sentido da injunção a rituais e a convenções sociais que, aplicados à linguagem, são vistos como comportamentos verbais necessários a certas circunstâncias, para as quais haveria um modo de dizer mais ou menos ritualizado ou, se não tanto, pelo menos convencionalizado, à maneira das regras de polidez. Note-se que o número de ocorrências com ênfase na construção composicional/estilo é de 13, número muito próximo das ocorrências da seção Para bem escrever cartas. Ora, nessa seção, o destaque é dado para a escrita de um gênero do discurso, e parece que a preocupação do livro escolar é justamente trabalhar com modelos de carta, à época um recurso de comunicação a distância nada desprezível, além de seu prestígio como forma de se estabelecer e manter relações sociais.

O destaque no conteúdo temático se explica pela presença de propostas-sintagma. Na proposta $n^{0}{ }^{16}{ }^{13}$, por exemplo, "Redação: minha viagem ao fundo do mar" (CRETELA, 1948, p. 228), não há nenhuma explicação além do próprio enunciado. Nesse caso, é interessante analisar a proposta de duas perspectivas distintas, mas relacionadas, a do autor e a do aluno. Por um lado, no caso do autor, a explicitação do tema ("minha viagem ao fundo do mar") conta com a implicitação de procedimentos gramaticais (principalmente, sintáticos) tomados como recursos para a produção do texto. Por outro lado, no caso do aluno, a gramática faria, talvez, mais sentido como réplica ao trabalho classificatório do período e da oração e, só pontualmente, a exercícios de estilo baseados em sintaxe. Notese, portanto, que, na relação entre ensino e aprendizagem, o aluno tenderia a olhar para o que lhe é dado como tema, já que a atenção classificatória do período e das orações, incluindo as relações lógicas estabelecidas entre as orações, nem sempre surtem o efeito desejado quando o que se aciona preferencialmente é o plano pragmático (e não o gramatical), fato que, contrariando a ordem gráfica do livro escolar, rompe a suposta continuidade formal da gramática para o texto.

Na proposta de escrita sob análise (Redação: minha viagem ao fundo do mar), considero, pelo que ficou dito, que a ênfase é dada ao conteúdo temático, já que nenhuma menção

13 Curiosamente, a proposta no 16 se repete. Na proposta no 19, mais uma vez, a indicação é "Redação: minha viagem ao fundo do mar" (CRETELA, 1948, p. 237). A princípio, parece ser um erro de tipografia, que teria escapado ao autor, aos editores e/ou aos tipógrafos. No entanto, por mais que essa repetição fosse involuntária (a Companhia Editoria Nacional primava pelo rigor nas suas edições), revela-se certo automatismo na elaboração das propostas de escrita, não só em função de uma suposta repetição involuntária, mas, sobretudo, pela destacabilidade quase proverbial (cf. MAINGUENEAU, 2008) dos temas, extraídos de diferentes contextos, e pela sua conhecida recorrência no trabalho diário do professor. 
é feita aos aspectos composicionais e estilísticos, a não ser pela nomeação da atividade solicitada: "Redação"; nem nenhum gênero do discurso está sendo solicitado (não se pede, por exemplo, para que o aluno produza uma carta).

O destaque na construção composicional/estilo (cf. Quadro 2) se explica pela recorrência do gênero carta, que caracteriza grande parte das propostas de escrita do livro. Estas últimas, ao solicitarem a produção de uma carta, obedecem a uma regularidade: sempre que a seção Para bem redigir cartas antecede a seção Exercícios, esta deixa de apresentar proposta-sintagma para introduzir a solicitação de uma carta, estabelecendo-se, portanto, um diálogo entre essas duas seções do livro. A alta ocorrência de solicitação de carta produz o alto número de propostas de escrita com destaque na construção composicional/estilo, uma vez que aquele gênero, conforme já foi dito, impõe exigências formais e estilísticas relacionadas a certo comportamento verbal, esperado ao menos para a época. Tome-se como exemplo a proposta $n^{\circ}$ 9, bastante parecida com as outras 12 que têm a mesma ênfase: "Redação: Carta de consolação a uma senhora aflita com o desaparecimento do filho (tratamento: a senhora)" (CRETELA, 1948, p. 201). Nessa proposta, há uma forma esperada para o gênero (carta com cabeçalho, vocativo, assinatura etc.) e um destinatário específico, bem como uma forma de tratamento, demandando um cuidado estilístico condizente com a situação simulada. A especificação temática, isto é, a consolação de uma mulher cujo filho desapareceu, serve menos como tema e mais como ilustração do tipo de carta (carta de conforto) e, portanto, da situação social em que essa proposta se insere, determinando, desse modo, seu estilo e composição. Assim, a ênfase está, ao mesmo tempo, na forma do gênero (construção composicional) e no destinatárioforma de tratamento-situação social de escrita (estilo), tudo isso orientado pelo viés da convenção.

Em Português para o ginásio, diferentemente de outros livros analisados do período, a ênfase dominante não recai, exclusivamente, no conteúdo temático, o qual não apresenta uma proporção marcadamente desigual em relação aos demais elementos. Nesse livro, os destaques no conteúdo temático e na construção composicional/estilo correspondem a 27 das 35 propostas apresentadas. Considerando-se a análise das ênfases nos elementos do gênero do discurso, o livro de Cretela, na década de 1940, parece ser, no que diz respeito aos livros analisados, um ponto fora da curva.

No entanto, deve-se observar que, apesar de sua discrepância em relação aos demais livros das décadas de 1930, 1940 e 1950 analisados, Português para o ginásio guarda, com eles, semelhanças consideráveis, evidenciando um enraizamento sócio-histórico no que diz respeito ao ensino de escrita. Apesar de apresentar ênfase variada e não exclusiva em conteúdo temático, esta última ainda é destacada e atrelada às propostassintagma. Somado a isso, há o fato de que, por mais que aposte em gêneros mais utilitários (naquele período, uma carta comercial ou social, por exemplo) e, dentre os textos literários estudados, inclua autores modernistas, como Manuel Bandeira, ainda 
faz do texto literário o modelo para uma concepção de língua como expressão do pensamento, pautada pela "simplicidade, correção, clareza, conveniência, harmonia, nobreza, precisão e naturalidade" (CRETELA, 1948, p. 169, grifos do autor), retomando, claramente, uma memória retórico-poética.

A literatura é quase consensual ao tratar do chamado período beletrista do ensino de português, em que predominava a atenção à gramática. Institucionalmente, esse período teria vigorado da fundação da disciplina de português, no Colégio Pedro II, em meados do século $X I X$, até meados do século $X X$, mas dataria já do ensino jesuítico, no século XVI. De acordo com Soares (2002), entre 1950 e 1960, por causa da força da tradição cujas raízes remetem ao ensino jesuítico, a gramática tinha primazia sobre o texto. A permanência da tradicional Antologia Nacional, de Barreto e Laet, publicada em 1895, nos currículos escolares do século XX também pode ser correlacionada à longevidade do modelo beletrista de ensino de português, como defende, por sua vez, Razzini (2010). Para a autora, essa correlação se justifica especialmente pela atenção da Antologia à correção gramatical e pelo seu papel na "função mantenedora da tradição vernácula de extração lusitana" (RAZZINI, 2010, p. 55). Nesse período, o ensino de escrita costuma ser visto como reduzido à atribuição de temas, posição claramente expressa por Meserani (1995, p. 18), ao afirmar que, até os anos de 1950, "com um tema e um limite espacial ele [o aluno] tinha que escrever", pois, na visão desse autor, a "redação não era 'matéria dada'" (MESERANI, 1995, p. 12). Ainda segundo Soares (2002, p. 169), os anos de 1970 representam um hiato na "primazia da gramática no ensino de português". A esse respeito, Batista (1999, p. 549) argumenta que a disciplina passou a se organizar "em torno de um conjunto de atividades voltadas para o desenvolvimento da leitura, da redação, da linguagem oral e para o aprendizado gramatical", constituindo-se num "ensino procedimental", razão pela qual os livros didáticos de português passam "a apresentar unidades construídas de modo complexo, buscando articular os diferentes saberes e ordens de saberes em jogo".

Pode-se sugerir, portanto, que Português para o ginásio é um indício da ascensão da ênfase na construção composicional e da gradativa perda de força do modelo beletrista (que a literatura associa à ênfase no conteúdo temático), o qual, até os anos 1960, orientaria o ensino de português e, também, o ensino de escrita. Embora esse modelo beletrista só perca, de fato, sua força nos anos de 1970, Português para o ginásio pode ser visto como um exemplo do processo de enfraquecimento paulatino. A análise detalhada do livro quanto às ênfases dos elementos do gênero do discurso permite localizá-lo como um "livro de transição", que se funda na tradição consolidada até a sua publicação, mas que já sinaliza, por outro lado, o seu esgotamento, bem como o esgotamento das formas de se pensar a educação até aquele momento. Como lembram Freitas e Biccas (2009), após a Segunda Guerra Mundial, os debates sobre a educação podem ser traduzidos em um questionamento: se a educação não serve para desenvolver uma sociedade, serve para quê? O livro de Cretela, de certo modo, na distribuição de suas ênfases, faz ressoar essa pergunta, marcando, assim, dentre outras maneiras, seu aspecto de transitoriedade. 


\section{Considerações finais}

Neste artigo, propus o uso dos elementos do gênero do discurso (BAKHTIN, 2016) como ferramenta analítica para a descrição de dezesseis livros escolares de português que fizeram parte do corpus de minha pesquisa de mestrado, detectando, nos livros, qual ou quais desses elementos foi(ram) o(s) mais enfatizado(s). Reconhecendo o dialogismo investido em conteúdo temático, estilo e construção composicional, foi possível sugerir algumas tendências gerais do ensino de escrita entre 1930 e 2002, dentre as quais destaco: (1) entre 1930 e 1960, predominou a ênfase no conteúdo temático, embora a construção composicional já despontasse como concorrente, mas ainda associada ao conteúdo temático; (2) a partir dos anos 1970 até 2002, o número de propostas de escrita passa a ser menor, mas é possível observar o crescimento proporcional da ênfase na construção composicional em detrimento do até então dominante conteúdo temático; e (3) o estilo não teve um papel destacado nas atividades de escrita sugeridas nos livros escolares analisados. Este último dado é muito relevante porque a ausência desse destaque nas propostas vem acompanhada pela concepção de escrita da qual faz parte integrante o estudo gramatical, no qual, por sua vez, se inclui o trabalho com o estilo. É ainda relevante o fato de que o ensino de gramática (sintaxe, especialmente) não é explicitamente ligado ao ensino de escrita, nem o ensino de noções de estilo é sempre explicitamente ligado ao ensino de sintaxe.

Além dessas tendências gerais, a análise permitiu observar que nem tudo num livro se encaixa nessas tendências. Como vimos, em Português para o ginásio, temos o que chamei um "ponto fora da curva", pois é um livro que retoma características padronizadas e, ao mesmo tempo, antecipa características ainda por se imporem.

Com esses resultados, nos termos apresentados no artigo, o uso analítico dos elementos do gênero do discurso - conteúdo temático, estilo e construção composicional - mostrouse bastante produtivo no estudo do ensino de escrita em livros escolares de português. Longe de serem tomados como categorias para classificar gêneros, tais elementos são uma possibilidade de, sistematicamente, reencontrar o histórico nas formas de se ensinar escrita propostas em diferentes períodos.

\section{Agradecimentos}

Agradeço a Manoel Corrêa pelas inúmeras contribuições a este trabalho e à Fundação de Amparo à Pesquisa do Estado de São Paulo (FAPESP) pelo financiamento (processo no: 2017/24562-9). 


\section{REFERÊNCIAS}

BAKHTIN, M. Os gêneros do discurso. Tradução Paulo Bezerra. São Paulo: Ed. 34, 2016.

BATISTA, A. Um objeto variável e instável: textos, impressos e livros didáticos. In: ABREU, M. (org.). Leitura, história e história da leitura. Campinas: Mercado das Letras/ FAPESP/ALB, 1999. p. 529-576.

CEGALLA, D.; ROCHER, D. Português: 4ª série ginasial. Nacional, 1966.

CRETELA, J. Português para o ginásio: 3ª e 4ª séries. São Paulo: Nacional, 1948.

CORRÊA, M. Bases teóricas para o ensino da escrita. Ling. (dis)curso. v. 13, n. 3, p. 481513, 2013.

CORRÊA, M. Relações intergenéricas na análise indiciária de textos escritos. Trab. Ling. Aplic., v. 45, n. 2, p. 205-224, 2006.

FREITAS, P. O nosso idioma: sintaxe das categorias gramaticais. São Paulo: Nacional, 1938.

FREITAS, M.; BICCAS, M. História social da educação no Brasil (1926-1996). São Paulo: Cortez, 2009.

GUILHAUMOU, J.; MALDIDIER, D. Efeitos do arquivo: a análise do discurso no lado da história. In: ORLANDI, E. (org.). Gestos de leitura: da história no discurso. Tradução Suzy Maria Lagazzi e José Horta Nunes. Campinas: UNICAMP, 2014. p. 169-190.

MESERANI, S. O intertexto escolar: sobre leitura, aula e redação. São Paulo: Cortez, 1995.

IMBRUNIZ, C. Elementos para uma memória discursiva do ensino de escrita: livros escolares de português (1930-2002). 2019. Dissertação (Mestrado em Filologia e Língua Portuguesa) - Faculdade de Filosofia, Letras e Ciências Humanas, Universidade de São Paulo, São Paulo, 2019.

IMBRUNIZ, C. Livros escolares e ensino de escrita: selecionando material entre a linguística e a história. Investigações, v. 31, n. 2, p. 429-457, 2018.

MAINGUENEAU, D. Cenas da enunciação. São Paulo: Parábola Editorial, 2008. 
MEDEIROS, R. Representações do ensino da leitura: as aulas de português na escola secundária brasileira (séculos XIX e XX). 2019. Tese (Doutorado em Linguística) Centro de Educação e Ciências Humanas, Universidade Federal de São Carlos, São Carlos, 2019.

PÊCHEUX, M. Discurso: estrutura ou acontecimento. Tradução Eni Orlandi. Campinas: Pontes, 2015.

RAZZINI, M. História da disciplina português na escola secundária brasileira. Tempos e Espaços em Educação, v. 4, p. 43-58, 2010.

SOARES, M. Português na escola: uma disciplina curricular. In: BAGNO, M. (org.). Linguística da norma. São Paulo: Edições Loyola, 2002. p. 155-177. 